\title{
Immunochemical Fecal Occult Blood Test for Detection of Advanced Colonic Adenomas and Colorectal Cancer: Comparison with Colonoscopy Results
}

\author{
Bianca Rosa Viana Freitas, ${ }^{1}$ Cristiane Kibune Nagasako, ${ }^{2}$ Celia Regina Pavan, ${ }^{2}$ \\ Sônia Letícia Silva Lorena, ${ }^{1}$ Fabio Guerrazzi, ${ }^{2}$ Cláudio Saddy Rodrigues Coy, ${ }^{3}$ \\ Maria de Lourdes S. Ayrizono, ${ }^{3}$ and Maria Aparecida Mesquita ${ }^{1}$ \\ ${ }^{1}$ Disciplina de Gastroenterologia, Departamento de Clínica Médica, Universidade Estadual de Campinas, \\ Rua Tessália Vieira de Camargo 126, Campinas 13083-887, Brazil \\ ${ }^{2}$ Gastrocentro, Universidade Estadual de Campinas, Rua Carlos Chagas 420, Campinas 13083-878, Brazil \\ ${ }^{3}$ Departamento de Cirurgia, Universidade Estadual de Campinas, Rua Tessália Vieira de Camargo 126, Campinas 13083-887, Brazil
}

Correspondence should be addressed to Maria Aparecida Mesquita; m.aparecida.mesquita@gmail.com

Received 13 August 2013; Accepted 26 September 2013

Academic Editor: R. Eliakim

Copyright (C) 2013 Bianca Rosa Viana Freitas et al. This is an open access article distributed under the Creative Commons Attribution License, which permits unrestricted use, distribution, and reproduction in any medium, provided the original work is properly cited.

\begin{abstract}
Background. Fecal immunochemical tests (FITs) have been used for colorectal cancer (CRC) screening in several countries. There is lack of information concerning diagnostic performances of this method in Brazil. Methods. Patients scheduled for elective colonoscopy provided one stool sample one week before colonoscopy. The accuracy of a qualitative FIT for detection of CRC and advanced adenomas was determined. Results. Overall 302 patients completed the study. Among them, 53.5\% were high risk patients referred for screening or surveillance. Nine (3\%) CRCs and 11 (3.6\%) advanced adenomas were detected by colonoscopy. Sensitivity and specificity for CRC were, respectively, $88.9 \%$ and $87.6 \%$. For advanced adenomas, sensitivity was $63.6 \%$ and specificity $87.6 \%$. Conclusion. Our results showed good sensitivity and specificity of the FIT for detecting advanced neoplasias. This method may be a valuable tool for future screening programs in Brazil.
\end{abstract}

\section{Introduction}

Colorectal cancer (CRC) is a major cause of cancer morbidity and mortality worldwide $[1,2]$. Over the last years there has been an increase in the reported incidence in Brazil, with estimates for 2012 of 26.2 new cases/100.000 for men and 25.6/100.000 for women in the regions with higher incidence rates [3]. In addition, analysis of CRC mortality in five Brazilian capitals showed an increasing and constant trend over the period of 1980-2009 [4].

The adenoma-carcinoma pathway is considered to be responsible for the majority of CRC [5]. Recent data from a long-term follow-up study showed that removal of adenomatous polyps was associated with a $53 \%$ reduction in mortality from CRC [6]. Considering the decrease in CRC incidence and mortality associated with population screening for CRC and precancerous lesions [7] guidelines in several countries recommend that adults from the general population at average risk should start screening at 50 years of age $[1,8,9]$. One of the proposed screening strategies is the survey with high sensitivity $(\geq 70 \%)$ fecal occult blood test (FOBT).

The traditional method to detect fecal occult blood has been the guaiac-based test (G-FOBT) that detects the peroxidase-like activity of hemoglobin. Although G-FOBT screening has been shown to reduce CRC incidence and mortality [7], the sensitivity of this method in detecting CRC and advanced adenomas has been shown to be low [10]. Another disadvantage of the G-FOBT is that it requires dietary restriction, since it is not specific for human blood and can produce false-positive results when red meat and fruits or vegetables containing peroxidase are ingested. In addition, bleeding in the upper gastrointestinal tract secondary to 
aspirin and nonsteroidal anti-inflammatory drugs can also produce false-positive tests.

More recently, the replacement of G-FOBT by immunochemical fecal occult blood tests (FITs) has gained acceptance in the literature. Many authors now recommend that FIT should substitute G-FOBT for CRC screening [11]. FITs use antibodies directed against human hemoglobin, are highly specific for detecting human blood of colonic origin, and thus are not affected by diet or medications. In addition, several studies have demonstrated the superior diagnostic performance of FITs in detecting both colonic adenomas and cancers in comparison with standard G-FOBT [12-14].

Considering the lack of information regarding the diagnostic accuracy of FIT for advanced neoplasias in Brazil, the aim of the present study was to assess prospectively the sensitivity and specificity of a FIT in detecting CRC and advanced adenomas using colonoscopy as the reference test.

\section{Subjects and Methods}

All consecutive patients scheduled for elective colonoscopy at our university hospital endoscopy unit from July 2009 to July 2010 were invited to bring a stool sample on the day of the educational session about colonoscopy, which takes place one week before the exam. All patients who underwent colonoscopy and provided the stool sample were initially included in the study. Those with incomplete colonoscopy (which did not reach the cecum) and noncancerous bleeding lesions at the time of colonoscopy, such as inflammatory bowel disease or bleeding hemorrhoids, were excluded from the analysis.

The study was approved by the Ethics Committee of our institution.

2.1. Colonoscopy and Histopathological Analysis. Before colonoscopy a questionnaire containing clinical and epidemiological data of the patient was completed. Colonoscopies were performed or supervised by experienced endoscopists who were blinded to the FIT results.

Polyps identified at the time of the exam were characterized by number, size, colonic location (proximal or distal to the splenic flexure), and endoscopic appearance. All polyps were removed and sent for histological analysis. Adenomas were classified by number, size, location, and histologic characteristics (tubular, tubulovillous, or villous).

Advanced adenoma was defined as either an adenoma sized $>1 \mathrm{~cm}$, or with villous or tubulovillous pattern, or with severe dysplasia [15].

For the purpose of analysis, in those cases with multiple polyps classification was based on the most histologically advanced lesion. Patients with diverticular diseases or nonbleeding hemorrhoids were considered as having normal colonoscopic findings.

2.2. Fecal Immunochemical Test. The FIT used in the current study was the Feca-Cult One Step Test (Alamar Tecno Científica Ltda) which is an immunochromatographic test for the qualitative determination of human hemoglobin in feces. The manufacturer's quoted cutoff hemoglobin concentration
TABLE 1: Demographic characteristics of the study population.

\begin{tabular}{lc}
\hline Characteristics & $N(\%)$ \\
\hline Age in years (mean \pm SD) & $56 \pm 14$ \\
$<50$ & $80(26.5)$ \\
$\geq 50$ & $222(73.5)$ \\
Gender & \\
$\quad$ Females & $194(64.2)$ \\
$\quad$ Males & $108(35.8)$ \\
Personal history of CRC & $80(26.5)$ \\
Family history of CRC & $36(11.9)$ \\
\hline
\end{tabular}

is $0.2 \mu \mathrm{g} \mathrm{Hb} / \mathrm{mL}$. FIT was performed in a single sample taken from a bowel movement one week before colonoscopy. All tests were performed by the same investigator, and borderline positive results (faint bands) were interpreted as positive.

2.3. Statistical Analysis. CRCs and advanced adenomas were analysed separately. Continuous variables were reported as mean \pm SD and categorical variables were reported as percentages. Comparisons of the results were performed by the Mann-Whitney $U$ test, Student's $t$-test, and Fisher's exact test as appropriate. The diagnostic value of FIT for detecting advanced adenomas and CRCs was assessed by calculating the sensitivity and the specificity of the test. All statistical analyses were carried out using SPSS version 20.0 for Windows (SPSS, Inc., Chicago, IL, USA). $P$ values $<0.05$ were considered to be statistically significant.

\section{Results}

Overall 302 patients were included in the study (Figure 1). Demographic characteristics of the study population are summarized in Table 1. Mean age was $56 \pm 14$ years, 73.5\% were $\geq 50$ years, and $64.2 \%$ were females.

Family history of CRC affecting one or two first-degree relatives, diagnosed at age $\geq 50$ years in all cases, was reported by $36(11.9 \%)$ patients.

The main indications for colonoscopy are shown in Table 2. It can be seen that $42 \%$ of patients were referred for colonoscopy because of symptoms, while $15.5 \%$ were high risk patients referred for screening and 38\% for surveillance (polyps or previous surgery for CRC).

3.1. Colonoscopy Findings. Table 3 shows the colonoscopy findings in the study population. CRC was found in 9 patients (3\%) whereas advanced adenomas were detected in 11 patients (3.6\%). The mean age of patients with CRC was $68 \pm 10$ years (53-78 years) and 89\% were females. All cases were adenocarcinomas, and $55.6 \%$ were well-differentiated tumors. In 6 patients $(66.7 \%)$ the tumor was located in the distal colon. Two patients (22.2\%) had a family history of CRC. Eight of them had no previous colonoscopy, while one had one adenoma in a previous examination.

The mean age of patients with advanced adenomas was $65 \pm 13$ years, and $63.6 \%$ were females. The location of the lesions was the distal colon in $63.6 \%$ of the cases. Advanced adenomas size ranged from 12 to $40 \mathrm{~mm}$, and the mean 


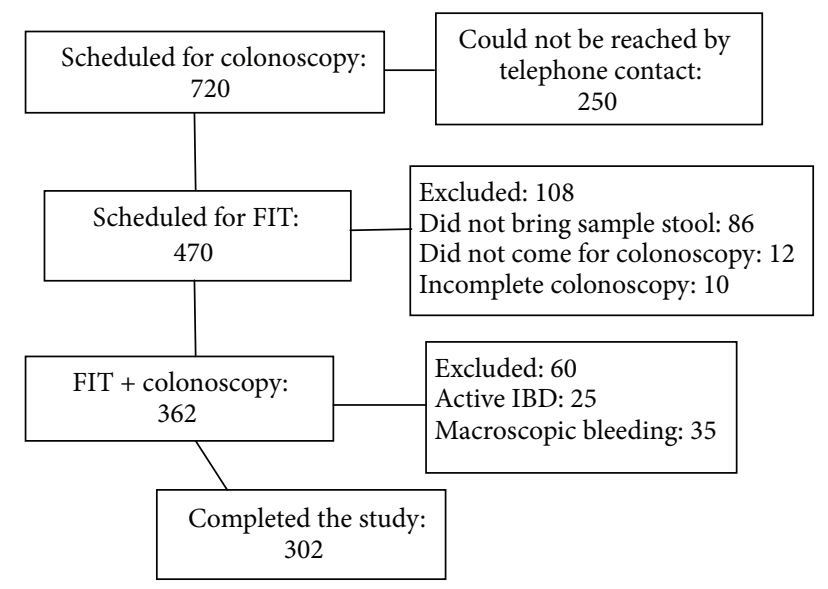

FIGURE 1: Flow chart of entry into the study.

TABLE 2: Main indications for colonoscopy in the study population.

\begin{tabular}{lc}
\hline Indications & $N(\%)$ \\
\hline Symptoms & $126(42)$ \\
(i) Altered bowel habits & $49(38.8)$ \\
Diarrhea & $27(21.4)$ \\
Constipation & $19(15)$ \\
Alternating bowel habit & $3(2.4)$ \\
(ii) Abdominal pain & $28(22.2)$ \\
(iii) Anemia & $16(12.7)$ \\
(iv) Weight loss & $9(7.2)$ \\
(v) More than one of the symptoms above & $16(12.7)$ \\
(vi) Other symptoms & $12(6.4)$ \\
Screening (high risk patients) & $47(15.5)$ \\
(i) Inflammatory bowel disease & $19(40.4)$ \\
(ii) Family history of CRC & $14(29.8)$ \\
(iii) Previous G-FOBT + & $6(12.8)$ \\
(iv) Others & $8(17)$ \\
Surveillance & $115(38)$ \\
(i) Personal history of CRC & $80(69.6)$ \\
(ii) Polyps & $35(30.4)$ \\
Others & $14(4.5)$ \\
Total & $\mathbf{3 0 2 ( 1 0 0 )}$ \\
\hline
\end{tabular}

TABLE 3: Colonoscopy findings in the study population.

\begin{tabular}{lc}
\hline Colonoscopy findings & $N(\%)$ \\
\hline Normal & $157(52)$ \\
Polyps & $73(24)$ \\
$\quad$ Hyperplastic & $27(9)$ \\
$\quad$ Adenoma & $35(11.4)$ \\
$\quad$ Advanced adenoma & $11(3.6)$ \\
Diverticular disease & $44(14.6)$ \\
Inflamatory bowel disease & $17(5.7)$ \\
CRC & $9(3)$ \\
Others & $2(0.7)$ \\
Total & $\mathbf{3 0 2 ( 1 0 0 )}$ \\
\hline
\end{tabular}

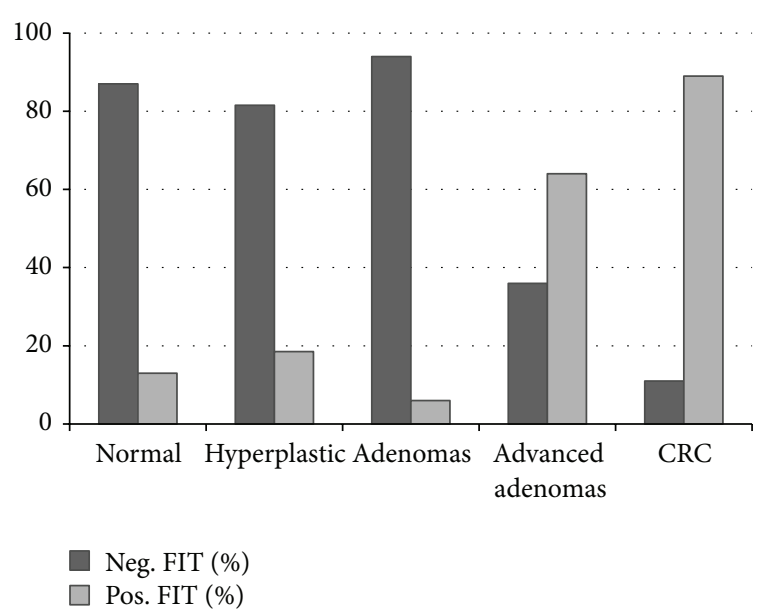

FIGURE 2: FIT positivity in relation to the colonoscopic findings.

number of lesions was $3 \pm 2$. In 6 patients (55\%), the adenomas were of the villous type. Two patients underwent colonoscopy because of polyps in previous exams. None of them had family history of CRC.

3.2. FIT Results. In 50 patients (16.5\%) the FIT was positive (borderline positive in two cases). Figure 2 illustrates the positivity rate of the test in relation to the colonoscopic findings: $16.7 \%$ in patients with normal colonoscopy, $18.5 \%$ in hyperplastic polyps, $5.5 \%$ in adenomas, $63.6 \%$ in advanced adenomas, and $88.9 \%$ in CRC. There was a statistically significant association $(P=0.001)$ between FIT positivity and advanced adenomas and CRC.

3.3. FIT Performance. Table 4 shows the FIT performance in detecting advanced adenomas and CRC. FIT sensitivity for CRC was $88.9 \%$, whereas specificity was $87.6 \%$. For advanced adenomas, the test sensitivity was $63.6 \%$ and the specificity $87.6 \%$.

The predictive positive value (PPV) for CRC and advanced adenoma was $18.6 \%$ and $16.7 \%$, respectively, while the correspondent negative predictive value (NPV) was $99.6 \%$ and $98.4 \%$.

\section{Discussion}

In this colonoscopy-controlled study we assessed the sensitivity and specificity of a qualitative FIT for detection of CRC and advanced adenomas. The sensitivity of $88.9 \%$ and specificity of $87.6 \%$ for CRC are within the range of 70 $100 \%$ sensitivity and $80-97 \%$ specificity reported in other studies using FITs [16-18]. For example, three studies that used the quantitative test OC-Sensor reported the sensitivity and specificity for CRC as 80\%/89\% [19], 84.6\%/89.8\% [12], and $100 \% / 91.7 \%$ [18].

The qualitative test is a chromatographic method, and the results are based on visual interpretation. Qualitative FIT permits simple, on-site analysis, does not require specific laboratory equipment, and therefore is less expensive than the automated quantitative FIT. However, the use of qualitative FITs has some disadvantages in relation to the quantitative 
TABLE 4: FIT performance in detecting CRC and advanced adenomas.

\begin{tabular}{lcc}
\hline & CRC $(n=9)$ & Advanced adenomas $(n=11)$ \\
\hline Sensitivity \% (IC 95\%) & $88.9(52-99)$ & $63.6(31-89)$ \\
Specificity \% (IC 95\%) & $87.6(83-91)$ & $87.6(83-91)$ \\
Positive predictive value \% (IC 95\%) & $18.6(8-33)$ & $16.7(7-31)$ \\
Negative predictive value \% (IC 95\%) & $99.6(97-99)$ & $98.4(96-99)$ \\
\hline
\end{tabular}

method. One of them is the possibility of interobserver variation in the analysis of the results, particularly in those cases of faint bands. The comparison of different qualitative tests showed variations in the frequency of faint bands, which may contribute to differences in the positivity results among tests [20]. According to manufacturers, faint bands should be regarded as borderline positive results. However, the analysis of several qualitative tests showed that, for some of them, borderline results should be rated negative rather than positive [21].

In addition, previous studies have shown great differences in the positivity rates of different qualitative FITs, which were mainly related to different thresholds for detection of hemoglobin in stool $[21,22]$. At the same time, there was a great variation in sensitivity and specificity for advanced neoplasias, which was strongly related to the positivity rate of the tests, indicating that lower cutoff values of fecal hemoglobin required to generate a positive result would render a higher test sensitivity. Therefore, test characteristics such as low frequency of faint bands and low cutoff value of fecal hemoglobin should be taken into account when selecting a qualitative test, reinforcing the importance of validation studies before implementation of the test in population-based screening.

Our study is also in agreement with those showing the superior performance of FIT in detecting CRC in comparison with advanced adenomas [23]. It has been proposed that multiple rounds, such as annual FIT testing, are likely to detect many of the lesions missed on initial screens before they progress to CRC [24]. Computed simulations indicated that five rounds of testing would increase the sensitivity for advanced adenomas to the acceptable value of $81 \%$ [19].

Our results are based on the analysis of one fecal sample. It has been suggested that FIT sensitivity increases with the number of samples tested, such as 2- or 3-day analysis of fecal samples, specially for advanced adenomas [25]. However, other authors have shown that double sampling of FIT was not superior to single sampling for detection of advanced adenomas and CRC [26]. Further studies are necessary to clarify this issue.

The design of the present study allowed the direct calculation of sensitivity and specificity of the FIT, since all patients underwent colonoscopy. This is an advantage in relation to the studies of screening populations, in which only subjects who test positive are referred for colonoscopy. Sensitivity and specificity are not influenced by the prevalence of disease, as confirmed in a previous study showing similar FIT results in screening and referral patients [27].
On the other hand, predictive values are determined by sensitivity, specificity, and also the prevalence of the disease. The prevalence of advanced neoplasias in our study group composed of patients at average risk along with those at high risk for CRC may be higher than that seen in average risk screening population, and consequently, the test predictive positive value may be lower in the screening population. That means that a larger proportion of those with positive screening tests will be found not to have the disease upon colonoscopic examination.

A pilot study was held in a small city located in the state of São Paulo from 2006 to 2007, using a qualitative FIT (Hemosure) for the screening of residents aged over 40 years and at average risk for CRC [28]. Those with positive tests were invited to undergo colonoscopic examination. Overall, 3,640 tests, $43.7 \%$ of the target population, were analyzed. Results were positive in 390 (10.7\%) exams. Colonoscopy was performed in 212 patients with positive FIT, showing polyps in 59 patients and adenocarcinoma in nine. All kits and colonoscopes were donations, and therefore cost analysis could not be performed.

Nowadays there is no public health policy for a nationwide CRC screening in Brazil. The implementation of a screening program in our country is highly dependent on public resources and therefore is critically affected by economic aspects. For example, the health department of the city of São Paulo, the most populated city in Brazil, recently concluded that at the moment it is not possible to implement a population screening for CRC in the city [29]. Considering the estimated target population (age 50-75 years) for 2011 as about two million people and a $50 \%$ participation rate, the use of biennial FIT (one sample) would require 550,000 kits and 55,000 colonoscopic examinations per year (considering the positivity rate of the test as $10 \%$ ), which is more than twice the number of examinations performed at present. No cost-benefit analysis was performed. The evaluation has also highlighted the need for pilot studies to assess feasibility and cost effectiveness of regional screening programs. Other aspects that should be addressed in future studies include the choice between qualitative or quantitative FITs and annual or biennial screening.

In conclusion, the FIT showed good sensitivity and specificity for the detection of advanced neoplasia in our study population, indicating that this method may be a valuable tool for future screening programs in Brazil.

\section{Conflict of Interests}

The authors declare that there is no conflict of interests regarding the publication of this paper. 


\section{References}

[1] J. A. Diaz and T. Slomka, "Colorectal cancer screening," The American Journal of Lifestyle Medicine, vol. 6, no. 3, pp. 196-203, 2012.

[2] J. Ferlay, D. M. Parkin, and E. Steliarova-Foucher, "Estimates of cancer incidence and mortality in Europe in 2008," European Journal of Cancer, vol. 46, no. 4, pp. 765-781, 2010.

[3] http://www.inca.gov.br/wps/wcm/connect/tiposdecancer/site/ home/colorretal.

[4] R. Mendonça, M. Valadão, A. C. Couto, and S. Koifman, "Trends of colorectal cancer mortality in five Brazilian capitals from 1980 to 2009," Cadernos Saúde Coletiva, vol. 20, pp. 329335, 2012.

[5] M. J. Arends, "Pathways of colorectal carcinogenesis," Applied Immunohistochemistry and Molecular Morphology, vol. 21, pp. 97-102, 2013.

[6] A. G. Zauber, S. J. Winawer, M. J. O’Brien et al., “Colonoscopic polypectomy and long-term prevention of colorectal-cancer deaths," The New England Journal of Medicine, vol. 366, no. 8, pp. 687-696, 2012.

[7] J. Faivre, V. Dancourt, C. Lejeune et al., "Reduction in colorectal cancer mortality by fecal occult blood screening in a French controlled study," Gastroenterology, vol. 126, no. 7, pp. 1674$1680,2004$.

[8] U.S. Preventive Services Task Force, "Screening for colorectal cancer: U.S. Preventive Services Task Force recommendation statement," Annals of Internal Medicine, vol. 149, no. 9, pp. 627637, 2008

[9] D. J. Leddin, R. Enns, R. Hilsden et al., "Canadian association of gastroenterology position statement on screening individuals at average risk for developing colorectal cancer: 2010," Canadian Journal of Gastroenterology, vol. 24, no. 12, pp. 705-714, 2010.

[10] H. Bleiberg, "Hemoccult should no longer be used for the screening of colorectal cancer," Annals of Oncology, vol. 13, no. 1, pp. 44-46, 2002.

[11] K. L. Flitcroft, L. M. Irwig, S. M. Carter, G. P. Salkeld, and J. A. Gillespie, "Colorectal cancer screening: why immunochemical fecal occult blood tests may be the best option," BMC Gastroenterology, vol. 12, article 183, 2012.

[12] D. I. Park, S. Ryu, Y. H. Kim et al., "Comparison of guaiac-based and quantitative immunochemical fecal occult blood testing in a population at average risk undergoing colorectal cancer screening," The American Journal of Gastroenterology, vol. 105, no. 9, pp. 2017-2025, 2010.

[13] A. Graser, P. Stieber, D. Nagel et al., "Comparison of CT colonography, colonoscopy, sigmoidoscopy and faecal occult blood tests for the detection of advanced adenoma in an average risk population," Gut, vol. 58, no. 2, pp. 241-248, 2009.

[14] L. Guittet, V. Bouvier, N. Mariotte et al., "Comparison of a guaiac and an immunochemical faecal occult blood test for the detection of colonic lesions according to lesion type and location," British Journal of Cancer, vol. 100, no. 8, pp. 1230-1235, 2009.

[15] S. J. Heitman, P. E. Ronksley, R. J. Hilsden, B. J. Manns, A. Rostom, and B. R. Hemmelgarn, "Prevalence of adenomas and colorectal cancer in average risk individuals: a systematic review and meta-analysis," Clinical Gastroenterology and Hepatology, vol. 7, no. 12, pp. 1272-1278, 2009.

[16] T. R. de Wijkerslooth, E. M. Stoop, P. M. Bossuyt et al., "Immunochemical fecal occult blood testing is equally sensitive for proximal and distal advanced neoplasia," The American Journal of Gastroenterology, vol. 107, no. 10, pp. 1570-1578, 2012.

[17] J. E. Allison, L. C. Sakoda, T. R. Levin et al., "Screening for colorectal neoplasms with new fecal occult blood tests: update on performance characteristics," Journal of the National Cancer Institute, vol. 99, no. 19, pp. 1462-1470, 2007.

[18] R. Hazazi, P. Rozen, M. Leshno et al., "Can patients at high risk for significant colorectal neoplasms and having normal quantitative faecal occult blood test postpone elective colonoscopy?" Alimentary Pharmacology and Therapeutics, vol. 31, no. 4, pp. 523-533, 2010.

[19] J. S. T. S. Droste, S. T. van Turenhout, F. A. Oort et al., "Faecal immunochemical test accuracy in patients referred for surveillance colonoscopy: a multi-centre cohort study," BMC Gastroenterology, vol. 12, article 94, 2012.

[20] B. Tannous, E. Lee-Lewandrowski, C. Sharples et al., "Comparison of conventional guaiac to four immunochemical methods for fecal occult blood testing: implications for clinical practice in hospital and outpatient settings," Clinica Chimica Acta, vol. 400, no. 1-2, pp. 120-122, 2009.

[21] H. Brenner, U. Haug, and S. Hundt, "Inter-test agreement and quantitative cross-validation of immunochromatographical fecal occult blood tests," International Journal of Cancer, vol. 127, no. 7, pp. 1643-1649, 2010.

[22] J. E. Allison, C. G. Fraser, S. P. Halloran, and G. P. Young, "Comparing fecal immunochemical tests: improved standardization is needed," Gastroenterology, vol. 142, no. 3, pp. 422-424, 2012.

[23] C. K. Wong, R. N. Fedorak, C. I. Prosser, M. E. Stewart, S. V. van Zanten, and D. C. Sadowski, "The sensitivity and specificity of guaiac and immunochemical fecal occult blood tests for the detection of advanced colonic adenomas and cancer," International Journal of Colorectal Disease, vol. 27, no. 12, pp. 1657-1664, 2012.

[24] M. J. Denters, M. Deutekom, P. M. Bossuyt, A. K. Stroobants, P. Fockens, and E. Dekker, "Lower risk of advanced neoplasia among patients with a previous negative result from a fecal test for colorectal cancer," Gastroenterology, vol. 142, no. 3, pp. 497504, 2012.

[25] A. H. C. van Roon, J. A. Wilschut, L. Hol et al., "Diagnostic yield improves with collection of 2 samples in fecal immunochemical test screening without affecting attendance," Clinical Gastroenterology and Hepatology, vol. 9, no. 4, pp. 333-339, 2011.

[26] F. A. Oort, S. T. van Turenhout, V. M. H. Coupé et al., "Double sampling of a faecal immunochemical test is not superior to single sampling for detection of colorectal neoplasia: a colonoscopy controlled prospective cohort study," BMC Cancer, vol. 11, article 434, 2011.

[27] S. T. van Turenhout, L. G. van Rossum, F. A. Oort et al., "Similar fecal immunochemical test results in screening and referral colorectal cancer," World Journal of Gastroenterology, vol. 18, no. 38, pp. 5397-5403, 2012.

[28] R. O. Perez, I. Proscurshim, G. P. S. Julião, M. Picolo, J. GamaRodrigues, and A. Habr-Gama, "Instalação e resultados preliminares de programa de rastreamento populacional de câncer colorretal em município brasileiro," ABCD: Arquivos Brasileiros de Cirurgia Digestiva, vol. 21, no. 1, pp. 12-15, 2008.

[29] São Paulo (cidade), Secretaria Municipal da Saúde, Coordenação de Epidemiologia e Informação, Boletim CEInfo Análise no. 06, Secretaria Municipal da Saúde, São Paulo, Brazil, 2012. 


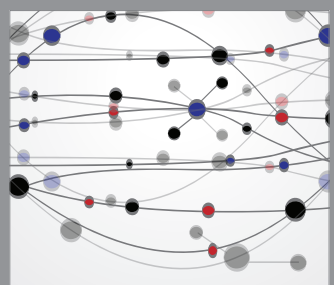

The Scientific World Journal
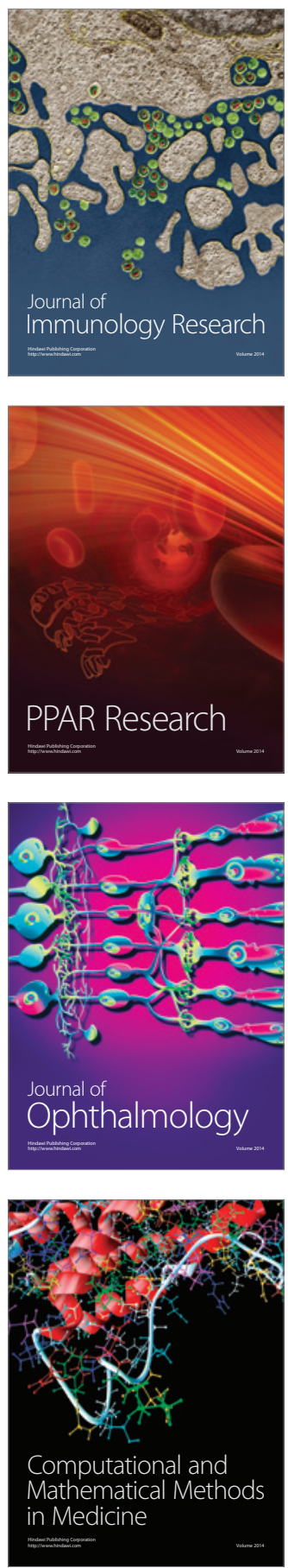

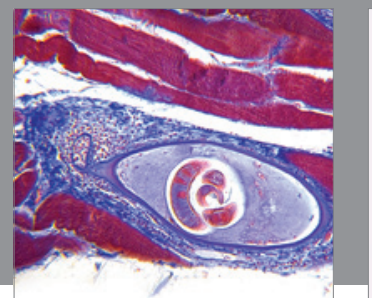

Gastroenterology

Research and Practice
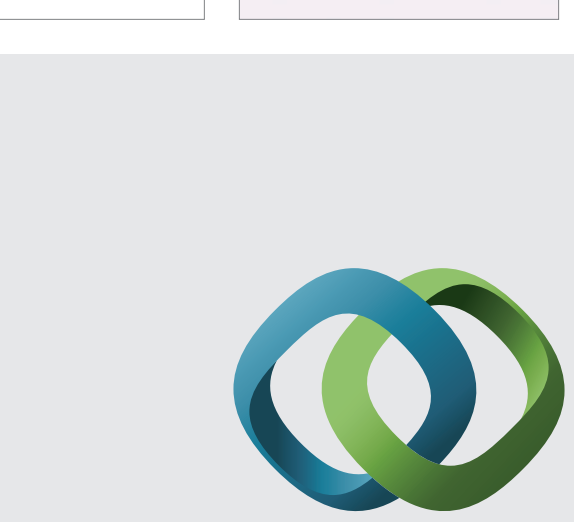

\section{Hindawi}

Submit your manuscripts at

http://www.hindawi.com
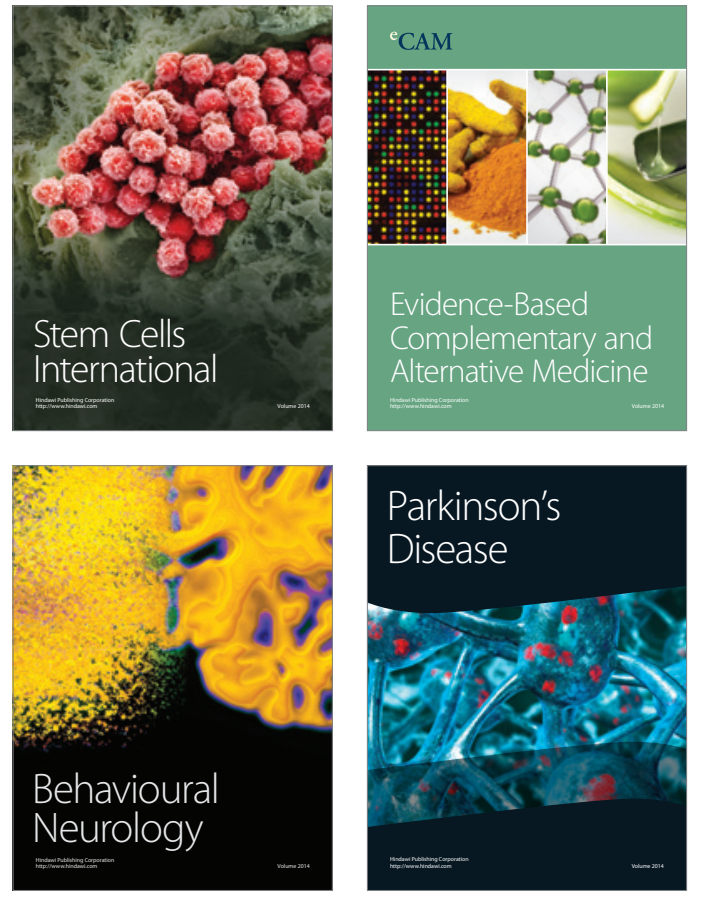
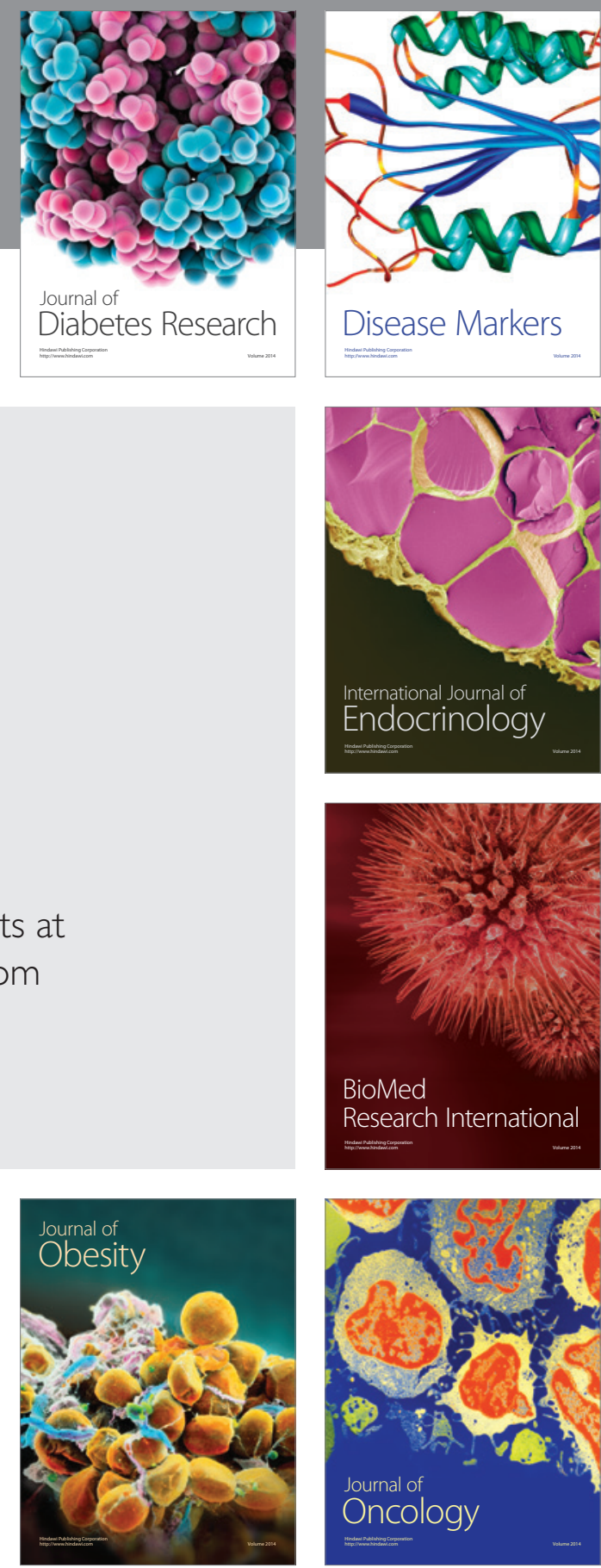

Disease Markers
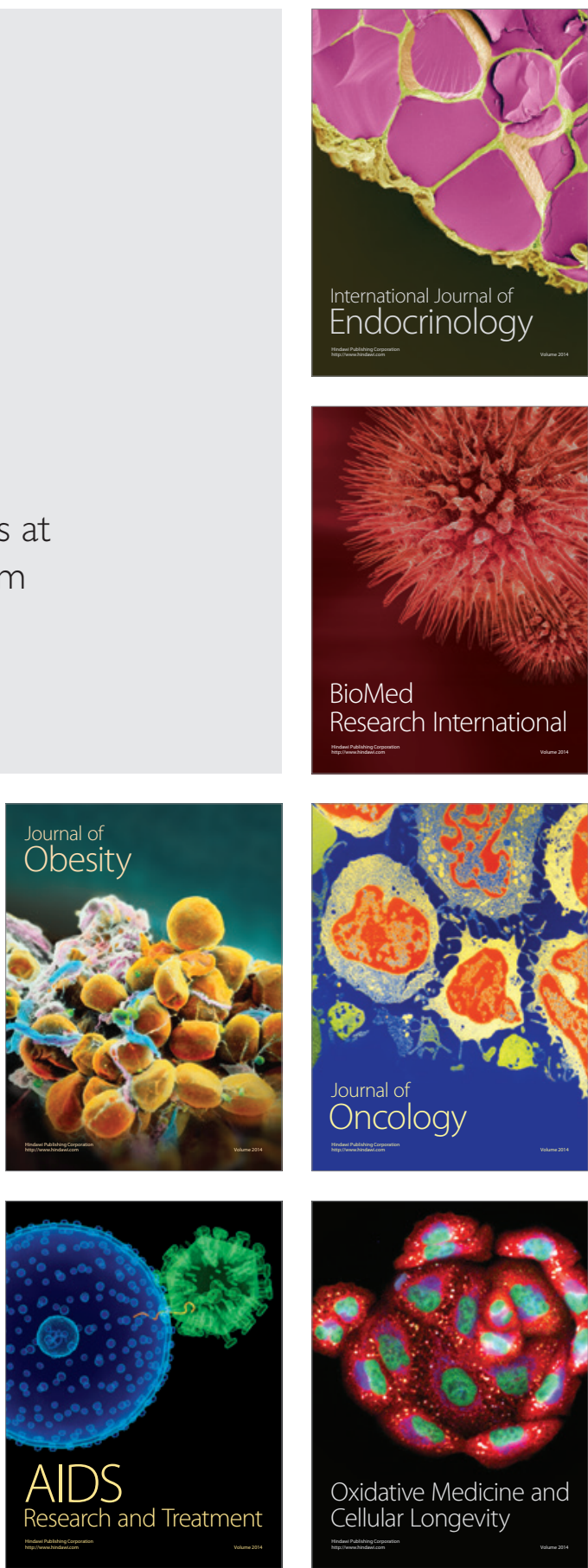